\title{
Nursing by Muskox Calves before, during, and after Helicopter Overflights FRANK L. MILLER, ${ }^{1}$ ANNE GUNN ${ }^{1,2}$ and SAMUEL J. BARRY ${ }^{1}$
}

(Received 28 April 1986; accepted in revised form 15 March 1988)

\begin{abstract}
Nursing bouts by 15 muskox (Ovibos moschatus) calves were measured to evaluate potential use of nursing behaviour as an indicator of muskox responses to helicopters. The muskox calves nursed 225 times during 313 hours of observation: $63 \%$ under undisturbed conditions; $12 \%$ when helicopter overflights took place; and $25 \%$ following those overflights. During exposure to the helicopter, the calf moved to the cow and then sometimes took the opportunity to nurse. Younger calves nursed relatively longer and more often than older calves; they also performed $68 \%$ of the nursings that occurred during helicopter overflights. Frequency and duration of nursing bouts are known to be related to the age of calves. This paper demonstrates that these aspects of nursing vary within or among muskox herds and concludes that observations of nursing at this level of effort cannot be employed with any confidence as a monitoring indicator of muskox response to helicopters.
\end{abstract}

Key words: nursing, muskox, calves, helicopter overflights, Northwest Territories, Canada

RÉSUMÉ. On a mesuré le temps des tétées de 15 veaux de boeufs musqués (Ovibos moschatus) pour évaluer l'utilisation potentielle du comportement lors des tétées comme un indicateur de la réaction du boeuf musqué à la présence d'hélicoptères. Les veaux ont tété 225 fois au cours des 313 heures d'observation: $63 \%$ tétaient dans des conditions sans perturbation, $12 \%$ alors que l'hélicoptère les survolait, et $25 \%$ après les survols. Quand l'hélicoptère était présent, le veau se dirigeait vers sa mère et en profitait parfois pour téter. Les veaux les plus jeunes tétaient relativement plus longtemps et plus souvent que les veaux plus âgés; $68 \%$ des tétées qui avaient lieu durant les survols de l'hélicoptère étaient faites par les plus jeunes. On sait que la fréquence et la durée des tétées sont reliées à l'âge des veaux. Cet article démontre que ces aspects des tétées varient à l'intérieur des troupeaux de boeufs musqués ou d'un troupeau à l'autre, et il conclut qu'on ne peut se fier aux observations sur les tétées à ce niveau de recherche, en tant qu'indicateur de contrôle de la réaction des boeufs musqués à la présence d'hélicoptères.

Mots clés: tétée, boeuf musqué, veaux, survols d'hélicoptères, Territoires du Nord-Ouest, Canada

Traduit pour le journal par Nésida Loyer.

\section{INTRODUCTION}

The advent of industrial development in the Arctic has been paralleled by efforts to describe and predict possible effects of those developments on the arctic ecosystem. Incumbent in proposals to construct pipelines across the Arctic Islands onto the mainland to carry oil and gas to southern markets was potential for serious disturbance of arctic ungulates when frequently exposed to low-flying aircraft, especially frequent lowlevel overflights by helicopters. Concerned about this possibility, Environment Canada initiated, through the Canadian Wildlife Service, a study to experimentally measure the short-term behavioural responses of Peary caribou (Rangifer tarandus pearyi Allen) and muskoxen (Ovibos moschatus Allen) to lowlevel helicopter overflights, which frequently are associated with industrial development (Miller and Gunn, 1979). The general hypothesis investigated was that low-level overflights by helicopter would introduce novel (foreign) stimuli into the exposed animal's environment, causing immediate and overt reactions (behavioural response), and that these could be measured under field conditions by aerial and ground observers.

It is known that the frequency of suckling of some young ungulates increases when the mother-young pair is exposed to human activities (Lent, 1974). In this light we attempted to test whether nursing patterns of muskox cow-calf pairs are a useful index of sensitivity to helicopter overflights for mitigation purposes. To do this we obtained data on a specific nursing behaviour to examine its variability. Our intent herein is to examine the feasibility of using nursing behaviour as a predictive index of response to helicopter overflights and to make available baseline data collected prior to industrial development.

\section{MATERIALS AND METHODS}

Nursing behaviour of 15 muskox calves was observed in summer 1977 on northeastern Prince of Wales Island (ca. $73^{\circ} 35^{\prime} \mathrm{N}$, $97^{\circ} 35^{\prime} \mathrm{W}$ ), Northwest Territories, Canada. Those observations involved calves in three muskox herds whose composition changed little during the study period and whose summer ranges were well known (Miller and Gunn, 1980: Fig. 1). Each muskox herd was named after a prominent landmark in the vicinity of its range.

The "Back Bay" muskox herd had 4 bulls, 9 cows, 2 juveniles, 4 yearlings and 8 calves. One calf was much younger, smaller and easily distinguishable from the other 7 calves throughout the study. This smallest calf is hereafter referred to as the "small calf" of the Back Bay herd, while the 7 relatively large and older calves are referred to collectively as the " 7 large calves" of the Back Bay herd. The small calf was only 1-2 d old when first seen and nearly 9 weeks old at the end of the study. We judged that the 7 large calves ranged in age from 4-6 to 12-14 weeks during the study. Calves of the Back Bay herd were observed on 25 occasions between 19 June and 16 August 1977.

The "Allen Lake" muskox herd had 5 bulls, 2 cows, 1 yearling and 2 calves. One of the calves was recognizably smaller than the other calf and remained so throughout the study. This younger, smaller calf is hereafter referred to as the "small calf" of the Allen Lake herd, while the other calf is referred to as the "large calf" of the Allen Lake herd. The small calf was judged to be only 2-3 weeks old when first seen and 9-10 weeks old when last observed. We judged that the large calf was 4-6 weeks old when first seen and 11-13 weeks old when last observed. Calves of the Allen Lake herd were observed on 17 occasions between 4 June and 24 July 1977.

\footnotetext{
${ }^{\mathrm{J}}$ Canadian Wildlife Service, 2nd Floor, 4999 - 98 Avenue, Edmonton, Alberta, Canada T6B 2X3

${ }^{2}$ Current address: Wildlife Management Division, Department of Renewable Resources, Government of the Northwest Territories, Coppermine,

Northwest Territories, Canada XOE OEO

(C)The Arctic Institute of North America
} 
The "Cape Briggs" muskox herd had 5 cows, 2 yearlings and 5 calves (no mature bull was present). All of the calves appeared similar in size and age and are hereafter referred to collectively as the " 5 large calves" of the Cape Briggs herd. We judged that they were 4-6 weeks old when first seen and 11-13 weeks old when last observed. Calves of the Cape Briggs herd were observed on only 4 occasions between 17 June and 2 August 1977.

We used a Bell-206B "Jet Ranger" turbo-helicopter to fly sets of passes overhead of each muskox herd at altitudes between 240 and $400 \mathrm{~m}$ above ground level (agl) during each trial exposure to the helicopter (see Miller and Gunn, 1980: Table 1 and text, for dates and details of helicopter overflights).

Ground observations were made only when the muskox herd was located where it could be overlooked from a prominence of land at several hundred metres without disturbing the muskoxen. We landed the helicopter on the far side of the prominence and the observers walked to a vantage point for viewing the animals. The helicopter flew away from the herd, remaining out of sight of the herd whenever possible. The overflight passes were initiated after a time lapse (mean $=187.2 \pm 24.69$ [SE] min). Ground observers worked in pairs, using 15-60X spotting scopes and $10 \mathrm{X}$ binoculars to watch muskoxen before, during and after the helicopter passes.

Each overflight pass began $8 \mathrm{~km}$ away from the herd, went over the herd, then continued in a straight line for $8 \mathrm{~km}$ beyond the herd before turning $180^{\circ}$ and making the next pass.

Observation periods (including helicopter overflights) were divided into three phases: (1) "undisturbed phase" - observations before helicopter flights took place (also included are all observations made during observation periods when there were no helicopter flights); (2) "harassed phase" - observations made during helicopter overflights, which included duration of the overflight (equals the time when the helicopter was audible to the observers) and the intervals between overflight passes (equals the time when the helicopter was no longer audible to the observers); (3) "recovery phase" - observations that took place after the set of helicopter overflights was completed.

We made ground observations of nursing behaviour patterns using the "focal-animal" continual sampling method (Altmann, 1974) along with a predetermined list of behaviours to record.

When muskoxen of the Back Bay herd were observed, one observer watched the small ("focal") calf and the other observer watched the seven large calves. When the Allen Lake herd was observed, one observer watched the small ("focal") calf and the other observer watched the large calf. When the Cape Briggs herd was observed, the calves watched by each observer varied. For each bout of nursing (referred to in this paper as nursing by the cow and suckling by the calf), we recorded which member of the cow-calf pair initiated and which terminated the bout. Only visual clues were used in these determinations, as the distances involved were too great to detect any possible auditory stimulation to begin an event. The event was considered initiated by whichever member of the pair moved in a deliberate manner to the other. We considered the event terminated by the calf if it stopped suckling and moved away while the cow held fast in place. When the cow was first to step away from the stillsuckling calf, we considered the event terminated by the cow.

We timed the duration of the nursing bout in seconds whenever possible. We defined apparent suckling by a calf for less than 5 seconds in duration as "attempted nursing," as we could not be sure that the calf was actually being nursed (and it often was not feasible to accurately time such a short duration after detection). Attempted nursings were not included in the subsequent analyses.

We tested hypotheses concerning calf age and disturbance responses by examining nursing bout frequency with Chisquare procedures. To do this we established calf age classes that are comparable to those used by Jingfors (1984). The distribution of observed nursings is directly proportional by observational phase to our sampling effort: undisturbed phases, $63.4 \%$ nursings vs. $64.1 \%$ time; harassed phases, $10.4 \%$ nursings vs. $9.8 \%$ time; and recovery phases, $26.2 \%$ nursings vs. $26.1 \%$ time. Because of this relationship we assumed that for any phase the frequency of nursing bouts would increase proportionally if more calves were observed for a longer time. We thus adjusted the observed frequencies for each phase and age class to reflect the maximum observation time during any phase and age class (i.e., $5640 \mathrm{~min}$ : undisturbed phase; 25-44 d age class). For example, if 30 nursing bouts were observed by $1-15 \mathrm{~d}$ old calves in $1255 \mathrm{~min}$, then 134.82 nursing bouts $(30 / 1255 \times 5640)$ would be observed in $5640 \mathrm{~min}$.

For the purpose of some of the Chi-square analyses we regarded these adjusted frequencies for the undisturbed phases to be expected for the other two phases (harassed and recovery) under the null hypothesis that disturbance causes no change in the frequency of nursing bouts.

Kruskal-Wallis, Mann-Whitney (Conover, 1980) and exact binomial test (Siegel, 1956) procedures were used to examine differences in nursing bout duration between observational phase and calf age.

\section{RESULTS}

We continually observed the three muskox herds during 134 observational phases (71 undisturbed, 29 harassed and 34 recovery), and we recorded 225 nursing bouts during those phases. Because of disproportionate sampling effort among herds and the different number of calves in each herd, analysis of nursing bout frequencies requires use of "adjusted "values (Table 1).

\section{Frequency of Nursing}

The calf age (only classes 1-15, 25-44 and 45-84 d used) and observational phase (Table 1$)$ are dependent $\left(X^{2}=11.06, \mathrm{df}=\right.$ $4 ; p<0.05$ ): that is, frequency of nursing varies with calf size (a measure of the influence of the calf's age) and observational phase (a reflection of whether the calf was calm or disturbed). More specifically, the nursing bouts during harassed and recovery phases were both dependent on the calf age $\left(X^{2}=347.88\right.$, df $=3 ; \mathrm{p}<0.05, \mathrm{X}^{2}=31.58, \mathrm{df}=3 ; \mathrm{p}<0.05$ respectively) when the undisturbed frequencies are viewed as the "expected" frequency for the other phases.

During harassment, young calves contributed a major portion $(50.6 \%)$ to the Chi-square: numerically a $114 \%$ increase in the number of nursing bouts over the undisturbed phase. During recovery phases the young calves also contributed the largest amount (99.9\%) to the Chi-square; in this instance, however, a $48 \%$ decrease occurred in the number of nursing bouts compared to those in undisturbed phases.

Nursing bout frequency was dependent on calf age $\left(\mathrm{X}^{2}=\right.$ 226.99 , $\mathrm{df}=4 ; \mathrm{p}<0.05$ ) during undisturbed periods when the 
TABLE 1. Distributions of observed and adjusted number of nursing bouts by calf age class and observational phase

\begin{tabular}{|c|c|c|c|c|c|c|c|c|c|}
\hline \multirow[b]{3}{*}{ Age class (d) } & \multicolumn{9}{|c|}{ Observational phase } \\
\hline & \multicolumn{3}{|c|}{ Undisturbed } & \multicolumn{3}{|c|}{ Harassed } & \multicolumn{3}{|c|}{ Recovery } \\
\hline & Obsv. bouts ${ }^{1}$ & Total time ${ }^{2}$ & Adj. bouts ${ }^{3}$ & Obsv. bouts & Total time & Adj. bouts & Obsv. bouts & Total time & Adj. bouts \\
\hline $1-15$ & 30.0 & 1255 & 134.82 & 14.0 & 273 & 289.23 & 14.0 & 1130 & 69.88 \\
\hline $16-24$ & 11.0 & 2737 & 22.67 & & & & & & \\
\hline $25 \cdot 44$ & 28.7 & 5640 & 28.70 & 8.2 & 701 & 65.97 & 10.1 & 1899 & 30.00 \\
\hline $45-84$ & 12.9 & 3276 & 22.21 & 2.0 & 151 & 74.7 & 5.7 & 1311 & 24.52 \\
\hline $85-93$ & 4.3 & 1511 & 16.05 & & & & 1.7 & 864 & 11.10 \\
\hline
\end{tabular}

"Number of nursing bouts adjusted to a "per calf" ' basis

${ }^{2}$ Total observation time.

${ }^{3}$ Adjusted number of nursing bouts based on maximal observation time ( $5640 \mathrm{~min}$ ),

expected nursing bouts are distributed equally among all five age classes. Thus, the young calves naturally nursed more frequently than did the relatively older calves.

\section{Nursing Position}

The nursing position of the calf relative to its mother was determined for 218 nursings. Calves suckled from the side during $91.3 \%$ of the nursings, and only two calves suckled from the rear by standing between the mother's hind legs $(8.7 \%$ of all nursings). The small calf of the Back Bay herd $(n=19)$ contributed $89.5 \%$ of the nursings from the rear and the remaining $10.5 \%$ (2) were by the large calf of the Allen Lake herd.

\section{Duration of Nursing}

We timed the duration of $172(76.4 \%)$ of the observed nursing bouts (Table 2). We found no differences in the mean duration of nursing between observational phases for calves $1-15$ dold (Kruskal-Wallis $\mathrm{H}=0.64, \mathrm{df}=2 ; \mathrm{p}>0.05$ ) and calves $25-44 \mathrm{~d}$ old $(\mathrm{H}=4.02, \mathrm{df}=2 ; \mathrm{p}>0.05)$.

By phase there was no difference in nursing duration among age classes of calves while harassed (Kruskal-Wallis $\mathrm{H}=4.02$, $\mathrm{df}=2 ; \mathrm{p}>0.05$ ). However, suckle duration declined with age for both the undisturbed period and the recovery period $(\mathrm{H}=$ 50.33 , df $=4 ; \mathrm{p}<0.05$ and $\mathrm{H}=16.05$, df $=3 ; \mathrm{p}<0.05$ respectively).

We found that with undisturbed calves less than $44 \mathrm{~d}$ old nursing bouts were distributed equally between those of short ( $<1 \mathrm{~min}$ ) and long ( $\geq 1 \mathrm{~min}$ ) duration (Table 3: binomial test; $\mathrm{p}>0.05$ ), whereas the nursing of older calves was consistently short (binomial test; $\mathrm{p}<0.05$ ).
When harassed, calves of all age classes (3) would nurse for short and long durations equally (Table 3: binomial test; $\mathrm{p}>0.05$ ).

While recovering from the disturbance, older calves $(>44 \mathrm{~d})$ nursed exclusively for short durations, as they did prior to harassment (Table 3: binomial test; $p<0.05$ ). Younger calves $(<45 \mathrm{~d})$ had no preference for short- or long-duration nursings.

\section{Temporal Distribution of Nursing Bouts}

In the undisturbed phase, the observed number of nursing bouts is skewed toward the younger ages. The following results concern the eight calves of the Back Bay herd during undisturbed phases of observation. For this herd we collected the widest range of data for the longest time: calves ranged in age from $1 \mathrm{~d}$ through $93 \mathrm{~d}$. No observations were made for this herd of calves between 10 and $25 \mathrm{~d}$ of age.

During the period 19-26 June we observed the small calf (1-9 d of age) for $1255 \mathrm{~min}$ and observed 30 nursing bouts: 2.39 bouts. calf ${ }^{-1} \cdot 100 \mathrm{~min}^{-1}$, or on the average $42 \mathrm{~min}$ required to record one nursing bout by one calf. During this same period the other seven calves (35-42 d old) only nursed six times: 0.07 bouts calf ${ }^{-1} \cdot 100 \mathrm{~min}^{-1}$, or $1464 \mathrm{~min}(24 \mathrm{~h})$ on the average to record one nursing bout by one calf. Further, for all eight calves when $26 \mathrm{~d}$ and older the frequency of nursing bouts was 63 in $4422 \mathrm{~min}$ of observation: 0.18 bouts. calf ${ }^{-1} \cdot 100 \mathrm{~min}^{-1}$, or 562 $\min (9 \mathrm{~h})$ on the average to record one nursing bout.

Omitting those undisturbed observational phases when no nursing bouts were recorded (only occurred for older calves), we found that there was a decrease (Mann-Whitney $U=124, \mathrm{df}=$ $1 ; \mathrm{p}<0.05)$ in the number of nursing bouts $\cdot \mathrm{calf}^{-1} \cdot 100 \mathrm{~min}^{-1}$ of observation between calves $1-9 \mathrm{~d}$ of age $(\mathrm{n}=6)$ and calves older than $26 \mathrm{~d}(\mathrm{n}=21)$. Similarly, the observational effort in

TABLE 2. Duration of nursing bouts (seconds) by calf age class and observational phase

\begin{tabular}{|c|c|c|c|c|c|c|c|c|c|c|c|c|}
\hline \multirow[b]{3}{*}{ Age class (d) } & \multicolumn{12}{|c|}{ Observational phase } \\
\hline & \multicolumn{4}{|c|}{ Undisturbed } & \multicolumn{4}{|c|}{ Harassed } & \multicolumn{4}{|c|}{ Recovery } \\
\hline & $\overline{\mathbf{x}}$ & sdev & $\mathrm{n}$ & $\mathrm{N}^{\mathrm{a}}$ & $\overline{\mathbf{x}}$ & sdev & $\mathrm{n}$ & $\mathbf{N}$ & $\overline{\mathrm{x}}$ & sdev & $\mathrm{n}$ & $\mathrm{N}$ \\
\hline $\begin{array}{r}1-15 \\
16-24\end{array}$ & $\begin{array}{l}92.1 \\
69.4\end{array}$ & $\begin{array}{l}73.7 \\
39.1\end{array}$ & $\begin{array}{r}17 \\
9\end{array}$ & $\begin{array}{l}30 \\
11\end{array}$ & 87.8 & 96.5 & 9 & 14 & 115.4 & 130.5 & 14 & 14 \\
\hline $25-44$ & 52.1 & 34.1 & 26 & 41 & 27.1 & 18.7 & 7 & 13 & 35.0 & 21.1 & 9 & 15 \\
\hline $45-84$ & 23.3 & 9.2 & 27 & 30 & 62.5 & 17.7 & 2 & 2 & 23.0 & 12.1 & 10 & 14 \\
\hline $85-93$ & 17.0 & 7.6 & 30 & 30 & & & & & 17.5 & 5.4 & 12 & 12 \\
\hline Total & 43.0 & 44.3 & 109 & 142 & 61.4 & 73.3 & 18 & 29 & 52.7 & 83.7 & 45 & 55 \\
\hline
\end{tabular}

${ }^{a} \mathrm{n}=$ number of bouts with a measured duration and $\mathrm{N}=$ number of bouts observed in total. 
TABLE 3. Number of nursing bouts by duration ( $<1 \mathrm{~min}$ vs. $\geq 1 \mathrm{~min}$ ) by calf age class and observational phase

\begin{tabular}{lcccc}
\hline \hline & & \multicolumn{3}{c}{ Observational phase } \\
\cline { 3 - 5 } Age class (d) & Duration (min) & Undisturbed & Harassed & Recovery \\
\hline $1-15$ & $<1$ & 6 & 5 & 7 \\
& $\geq 1$ & 11 & 4 & 7 \\
$16-24$ & $<1$ & 2 & & \\
& $\geq 1$ & 7 & & \\
$25-44$ & $<1$ & 15 & 6 & 7 \\
& $\geq 1$ & 11 & 1 & 2 \\
$45-84$ & $<1$ & 27 & 1 & 10 \\
& $\geq 1$ & 0 & 1 & 0 \\
$85-93$ & $<1$ & 30 & & 12 \\
& $\geq 1$ & 0 & & 0 \\
\hline \hline
\end{tabular}

minutes required to record one bout of nursing was higher (Mann-Whitney $\mathrm{U}=2, \mathrm{df}=1 ; \mathrm{p}<0.05$ ) for the older calves.

Regressing all non-zero nursing bouts, expressed as bouts.calf $\mathrm{f}^{-1} \cdot 100 \mathrm{~min}^{-1}(\mathrm{y})$, against the calf's age $(\mathrm{x})$, we found that a significant $(\mathrm{p}<0.05)$ portion of the variance was explained by $y=7.272 \cdot(x)^{-0.825}$ (adjusted $R^{2}=0.586$ ), a monotonically decreasing function. The significant $(p<0.05)$ relationship (inverse to the previous) found by regressing the observational effort, expressed as the number of minutes of observation required to record one nursing bout by one calf $(\mathrm{y})$, was $\mathrm{y}=$ $13.749 \cdot(x)^{0.825}$ (adjusted $R^{2}=0.586$ ), a monotonically increasing function. Thus the frequency of calf nursing drops significantly after the first week of life and the amount of observational effort required to observe nursings increases exponentially with the age of the calf.

\section{DISCUSSION}

Miller and Gunn $(1979,1980)$ showed that $200 \mathrm{~m}$ agl is a statistically significant threshold height for muskox responses to helicopter overflights; below that galloping responses occurred relatively more often than expected. All 28 harassed phases with observed nursings were associated with helicopter overflights

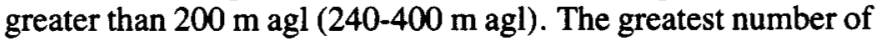
suckles during one series of six passes was during the observation with the overflights at the greatest altitudes $(260-400 \mathrm{~m} \mathrm{agl})$.

Most, if not all, suckles during harassed phases were likely opportunistic. The cow and her calf came together in response to harassing stimuli, and the calf took the opportunity to nurse. The small calf of the Back Bay herd nursed most frequently and preferentially nursed from the rear position during harassed phases. Nursing from the rear could probably be exhibited more often by persistent calves during opportunistic events, especially when the cow is not ready or is not expecting the calf to suckle. In 475 observations of nursing by undisturbed muskoxen in Alaska, Jingfors (1984) only saw two nursings from the rear. His findings seemingly support our belief that nursings during harassed phases were opportunistic, especially if nursing from the rear is the position more often opportunistically used by calves.

We concentrated on quantifying nursing as a possible monitoring indicator of responses to human activities, first, because cows with calves are usually the most responsive sex and age class (Miller and Gunn, 1979), and second, because nursing frequency for some ungulates is known to increase in associa- tion with response to disturbance (Lent, 1974). The frequency of nursing by some muskox calves was apparently increased by our helicopter overflights. Whether or not this type of disruption of activity (nurse-rest cycles) would have any short- or long-term detrimental effects on the well-being of muskox calves is unknown.

Observational bias may partially explain the relatively low number of observed suckles by the 13 large, individually unidentified calves compared to the two small calves ("focal calves"). However, the greater number and rates of observed suckles by the small calves of the Back Bay and the Allen Lake herds, compared to those values obtained from the 13 large calves, apparently reflects mainly the influence of calf's age on the frequency of nursing.

Sampling of muskox nursing behaviour is confounded by the lengthy calving period (March to June, usually peaking in May) because of the close relationship between frequency and duration of suckling and the calf's age (and possibly further complicated by the mother's age and experience). As our results show, the presence of a young calf in a herd with several other calves can cause marked variation in any analysis of nursing. Natural (undisturbed) variation in suckling behaviour could also result from annual differences in the behaviour of maternal cows due to their prevailing nutritional state or physical condition. Horejsi (1972), for example, described differences in suckling behaviour of bighorn sheep (Ovis canadensis) between two years characterized by "good and poor" forage conditions. Similarly, Jingfors (1984) described differences in nursing behaviour between two muskox populations, one of which was on "poorer" quality range.

We suggest a detailed consideration of the following by anyone contemplating studies of nursing behaviour of arctic ungulates in relation to man-induced foreign stimuli. Large sample sizes will be costly and difficult to obtain. (We used six ground observers in three pairs and two aerial observers during a three-month field period [29 May-25 August], and the project budget for field operations only was $\$ 140000$ in 1977 . This level of resource support was only possible through a special government program [Arctic Islands Pipeline Program]; normally available resources for such a study would be only a small fraction of this on an ongoing basis. Although the collection of data on nursing behaviour was only a minor part of the overall project, the above costs and field staff would have been necessary even if it had been the sole purpose of our study.) If you are using an aircraft, you must control the altitude and flight path to conform with the design of your study; therefore, you must pay for the use of the aircraft. (Our cost averaged ca. $\$ 400 \cdot h^{-1}$ for flight time and associated fuel caching - today's cost would be at least double.) Ideally, you should be in the field in contact with your study herds before calving actually starts to maximize the accuracy of age determination of the focal calves. Then, your field period must extend over at least two months, and preferably three, to obtain adequate sample sizes on a temporal basis during all phases of observation (undisturbed, harassed and recovery) because of the strong influence of the calf's age on the frequency of suckling (nursing bouts). For example, while watching the youngest calf, which contributed the largest sample of sucklings during undisturbed phases, it required on the average $21.5,57.4,247.8$ and 419.3 min of continual observation to obtain one nursing bout when the calf was 1-2, 4-9, 26-41 and $42-60 \mathrm{~d}$ old. 
For a full consideration of the behavioural aspects of suckling and the potential changes to suckling resulting from human activity, the researcher must measure by observational phase (undisturbed, harassed and recovery): (1) frequency of suckling; (2) member of pair initiating and terminating event; (3) durations of nursing bouts and changes in durations; (4) number of successful sucklings vs. unsuccessful (attempted) sucklings; (5) kinds and extent of mother-young contact; (6) the calf's age and the cow's age, experience, nutritional state and physical condition. The above data should be collected in a manner that allows analyses to be carried out using the continual observation times for (1) the "synchronized active time" of the cow-calf pair, (2) the "active time" of the cow only, and (3) the "active time" of the calf only to compare to the results based on the total continual observational time (active and inactive times for both the cow and the calf of each pair).

In conclusion, the frequency of suckling by the young calves increased in response to helicopter overflights. Such suckling may indicate increased security seeking by young calves as a result of human activities. However, the dependency of the frequency of nursing on the calf's age imposes sampling difficulties (especially with older calves, as infrequent behaviours are hard to sample) and limitations to comparing populations in different areas or years. Thus, we suggest that the use of nursing behaviour as an indicator of the effects of human activities on muskox calves is not currently feasible because measuring the many elements of nursing behaviour is complex and demands an exceptionally high level of sampling effort (and costs) and the necessity for refined field procedures to fully test such a relationship.

\section{ACKNOWLEDGEMENTS}

The Arctic Islands Pipeline Program, Polar Continental Shelf Project (PCSP), Energy, Mines and Resources Canada and the Canadian Wildlife Service (CWS) funded the project. We especially thank G.D. Hobson, Director, PCSP, for his continued support. We thank the other field observers: S. Hall, B.K. Herbert, A.J. Kennedy, D. Myers, K.E. Smyth and R.G. Thomson. We thank R.D. Cameron and J.L. Davis, Alaska Department of Fish and Game, K.T. Jingfors, Northwest Territories Wildlife Service, A. Radvanyi and W.E. Stevens, CWS, and one anonymous reviewer who reviewed earlier versions of the manuscript.

\section{REFERENCES}

ALTMANN, J. 1974. Observational study of behavior: sampling methods. Behaviour 49:227-267.

CONOVER, W.J. 1980. Practical nonparametric statistics. 2nd ed. New York: John Wiley \& Son. 493 p.

HOREJSI, B. 1972. Behavioral differences in bighom lambs (Ovis canadensis canadensis Shaw) during years of high and low survival. Northern Wild Sheep Council Symposium Proceedings 1972. Edmonton: Alberta Fish and Wildlife Division, Alberta Department of Lands and Forests. 51-73.

JINGFORS, K.T. 1984. Observations of cow-calf behaviour in free-ranging muskoxen. Biological Papers, University of Alaska, Special Report No. 4:105-109.

LENT, P.C. 1974. Mother-infant relationships in ungulates. In: Geist, V., and Walther, $F$., eds. The behaviour of ungulates and its relation to management. Morges, Switzerland: IUCN, New Series Publication No. 24. 1:14-55.

MILLER, F.L., and GUNN, A. 1979. Responses of Peary caribou and muskoxen to helicopter harassment. Canadian Wildlife Service Occasional Paper No. $40.90 \mathrm{p}$.

1980. Behavioural responses of muskox herds to simulation of cargo slinging by helicopter, Northwest Territories. Canadian Field-Naturalist 94:52-60.

SIEGEL, S. 1956. Nonparametric Statistics for the Behavioral Sciences. New York: McGraw-Hill Book Company. 312 p. 